\title{
ХІМІЧНА ІНЖЕНЕРІЯ
}

УДК 532.137

АНДРЕЄВ І. А., К. Т. Н., доценТ; ПІНЧУК А. Є., аспірант; КРАМАР О. В., магістрант

Національний технічний університет України

«Київський політехнічний інститут імені Ігоря Сікорського»

\section{ВІБРОЕКСТРУЗІЙНИЙ ПЛИН БЕТОННИХ СУМІШЕЙ У ПРАВИЛЬНОМУ ЧОТИРИКУТНОМУ ПІРАМІДАЛЬНОМУ КАНАЛІ}

Запропоновані спрощені формули для опису процесу віброекструзійного плину бетонних сумімей в прямокутних і правильних чотирикутних пірамідальних каналах.

Отримана формула розрахунку в'язкості за часом витікання певної кількості бетонної суміші з правильного чотирикутного пірамідального каналу безпосередньо в процесі віброекструзії.

Запропоновані формули зручні для подальщої математичної обробки, не мають обмежень у застосуванні, придатні для опису плину і реологічних властивостей будь-яких псевдоньютонівських рідин.

Ключові слова: плин бетону, пірамідальний канал, віброекструзія, фібробетонна суміш, в'язкість.

DOI: 10.20535/2617-9741.3.2021.241018

(C) Андреєв I. А., Пінчук А. С., Крамар О. В., 2021.

Постановка проблеми. Нові конструкційні фібробетонні матеріали в наш час все частіше застосовують замість традиційних бетонних і залізобетонних виробів. Формування фібробетону відноситься до нового напрямку промисловості і вимагає постійного удосконалювання. Найбільш ефективно використовувати властивості дисперсної арматури дозволяє спеціально розроблена технологія віброекструзії. Типове віброекструзійне устаткування містить дозатор-живильник розчину і віброекструдер для формування квадратних у поперечному перерізі стовпчиків, які мають правильні чотирикутні пірамідальні канали. Тому дуже важливим $є$ дослідження гідродинаміки плину бетонних сумішей i визначення іх реологічних властивостей в таких каналах.

Аналіз попередніх досліджень. При практичному визначенні реологічних властивостей бетонних (фібробетонних) сумішей використовується феноменологічний підхід, що приймає розглянутий матеріал, як однорідне ізотропне середовище. Про структуру бетонних сумішей робляться лише загальні застереження. Грунтуючись на представленнях суцільності, значно облегшується математичний опис плину, можливе введення таких макроскопічних параметрів, як тиск і температура.

Коли бетонна суміш знаходиться під впливом вібрації, тоді вона поводиться подібно рідини і тому найбільш придатними для розрахунку процесів і реологічних характеристик $є$ гідродинамічні теорії. При вирішенні задач плину враховується, що в умовах вібраційного поля, яке створюється стандартними вібраторами, бетонні (фібробетонні) суміші являють собою псевдоньютонівські системи [1].

Для одержання об'єктивних реологічних характеристик необхідно використовувати віскозиметри, плин матеріалу в яких моделював би процес переробки. Це є дуже важливим у випадку бетонних сумішей, які містять дисперсну арматуру, тому що від орієнтування фібр, що виникає через зсувні деформації, змінюється в'язкість всієї системи.

В процесі віброекструзії плин бетонної суміші здійснюється у вібраційному полі, що дозволяє переробляти системи з гранично високою міцністю первинної коагуляційної структури. Екструзія здійснюється за рахунок гідростатичного тиску фібробетонної суміші зі значно зниженою в'язкістю.

За допомогою «методу впливу» [2] була отримана формула опису процесу плину ньютонівської рідини в правильному чотирикутному пірамідальному каналі [3]:

$$
u_{r}=\frac{u_{r \max }\left(\cos 2 \varphi_{0}-\cos 2 \varphi_{1}\right)\left(\cos 2 \varphi_{0}-\cos 2 \varphi_{2}\right)}{\left(\cos 2 \varphi_{0}-1\right)^{2}}
$$


де $u_{r \max }$ - максимальна швидкість плину в центрі квадратного збіжного каналу, м/с; $\varphi_{0}-$ кут нахилу похилої стінки каналу до вертикалі $\left(\varphi_{0}<45^{\circ}\right)$, рад.; $\varphi_{1}, \varphi_{2}-$ кути нахилу до вертикалі проекцій поточного радіуса $r$ на площини yoz і хоz, відповідно, рад.

Розрахункова схема подана на рис. 1. Для зручності розрахунку початок сферичної системи координат ( $r, \theta, \varphi)$ вибрано у точці, де сходяться похилі стінки каналу.

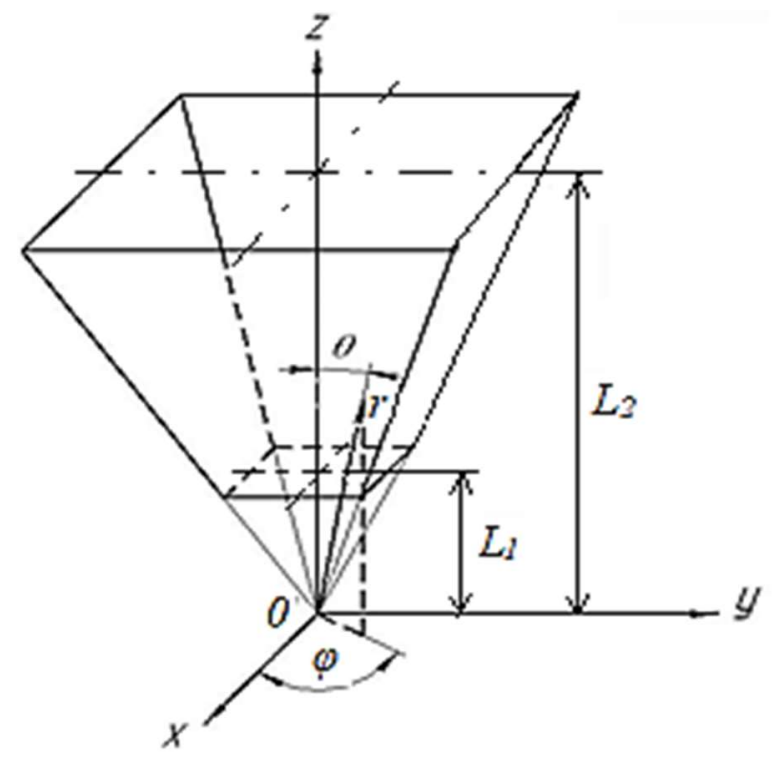

Рис. 1 - Розрахункова схема процесу плину в правильному чотирикутному пірамідальному каналі

Поточні кути $\varphi_{1}$ і $\varphi_{2}$ рівняння (1) визначають за формулами:

$$
\varphi_{1}=\operatorname{arctg}(\operatorname{tg} \theta \cdot \sin \varphi), \varphi_{2}=\operatorname{arctg}(\operatorname{tg} \theta \cdot \cos \varphi) .
$$

Характер розподілу відносних швидкостей у правильному пірамідальному каналі, розрахованих за формулою (1), показав їх близькість до експериментальних значень. Відносна похибка при цьому склала 4,79...5,15\% [4]. Крім того в роботі [2] було зазначено, що коректування формули, отриманої «методом впливу», необхідно здійснювати для каналів, які відрізняються за формою поперечного перерізу від квадратного. Невирішеною частиною наукової проблеми є визначення абсолютних значень величин, які характеризують плин і залежності реологічних характеристик фібробетонних сумішей в процесі віброекструзії від форми каналів, що звужуються.

Метою статті є представлення результатів пошукових досліджень, які були спрямовані на можливість розрахунку плину бетонних сумішей і визначення їх в’язкості безпосередньо в процесі віброекструзії в правильних чотирикутних пірамідальних каналах.

Виклад основного матеріалу. Правильний чотирикутний пірамідальний канал має квадратний поперечний переріз, тому скористаємось для визначення швидкості $u_{r \max }$ аналітичною формулою [5], що описує плин ньютонівської рідини у прямокутному каналі постійного поперечного перерізу зі сторонами $\mathrm{W}$ i Н у напрямках х і у (прямокутні координати $(\mathrm{x}, \mathrm{y}, \mathrm{z}))$ при $x=0,5 \mathrm{~W}, y=0,5 H$ : 


$$
u_{Z}=\frac{1}{\mu} \cdot \frac{\partial p}{\partial z}\left[\frac{y}{2}(y-H)+\frac{4 H^{2}}{\pi^{3}} \sum_{n=1,3, \ldots}^{\infty} \frac{1}{n^{3}} \cdot \sin \left(\frac{n \pi y}{H}\right) \cdot \frac{\operatorname{ch}\left(\frac{n \pi\left(x-\frac{W}{2}\right)}{H}\right)}{c h\left(\frac{n \pi W}{2 H}\right)}\right],
$$

де $p$ - тиск, МПа; $\mu$ - динамічна в'язкість, Пас.

Порівняємо максимальні швидкості плину у прямокутному каналі і у плоскій щілині, що мають однакову ширину $H$. Для цього побудуємо графік залежності $u_{z \max } / u_{n \max }=f(W / H)$ (рис. 2), де $u_{n \max }=-\frac{1}{8 \mu} \cdot \frac{\partial P}{\partial z} H^{2}-$ максимальна швидкість в плоскій щілині шириною $H$, м/с.

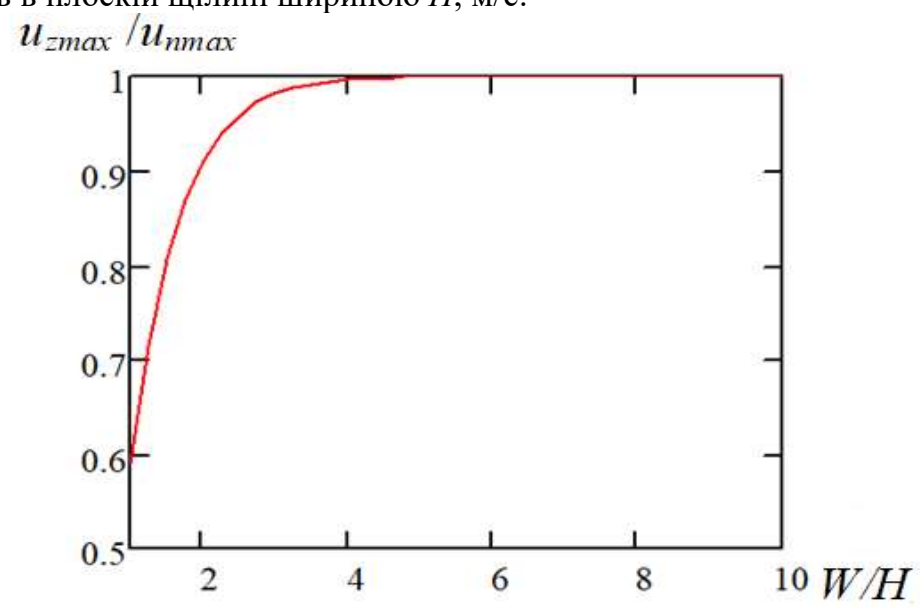

Рис. 2 - Графік залежності $u_{z \max } / u_{n \max }$ від $W / H$

Якщо ввести коефіцієнт зменшення швидкості $K_{u}=u_{z \max } / u_{n \max }$, який враховує зменшення швидкості плину в каналі прямокутного поперечного перерізу порівняно 3 плином між плоскими паралельними пластинами, тоді можна записати формулу для визначення максимальної швидкості плину в центрі прямокутного каналу у спрощеному вигляді:

$$
u_{z \max }=-\frac{K_{u}}{8 \mu} \cdot \frac{\partial P}{\partial z} H^{2}
$$

Для квадратного поперечного перерізу коефіцієнт зменшення швидкості $K_{u}=0,6$.

Застосовуючи рівняння (2) можна знайти витрату ньютонівської рідини у прямокутному каналі:

$$
Q=\int_{0}^{H} \int_{0}^{W} u_{Z} d x d y=\frac{1}{\mu} \cdot \frac{\partial p}{\partial z}\left[-\frac{W H^{3}}{12}+\frac{16 H^{4}}{\pi^{5}} \sum_{n=1,3, \ldots}^{\infty} \frac{1}{n^{5}} \cdot \operatorname{th}\left(\frac{n \pi W}{2 H}\right)\right] .
$$

Враховуючи, що об’ємна витрата ньютонівської рідини у плоскій щілині (плоский пуазейлевий плин) довжиною $H$ розраховується за формулою $Q_{n}=-\frac{1}{12 \mu} \cdot \frac{\partial p}{\partial z} H^{4}$, побудуємо графік залежності $Q / Q_{n}=f(W / H)$ 


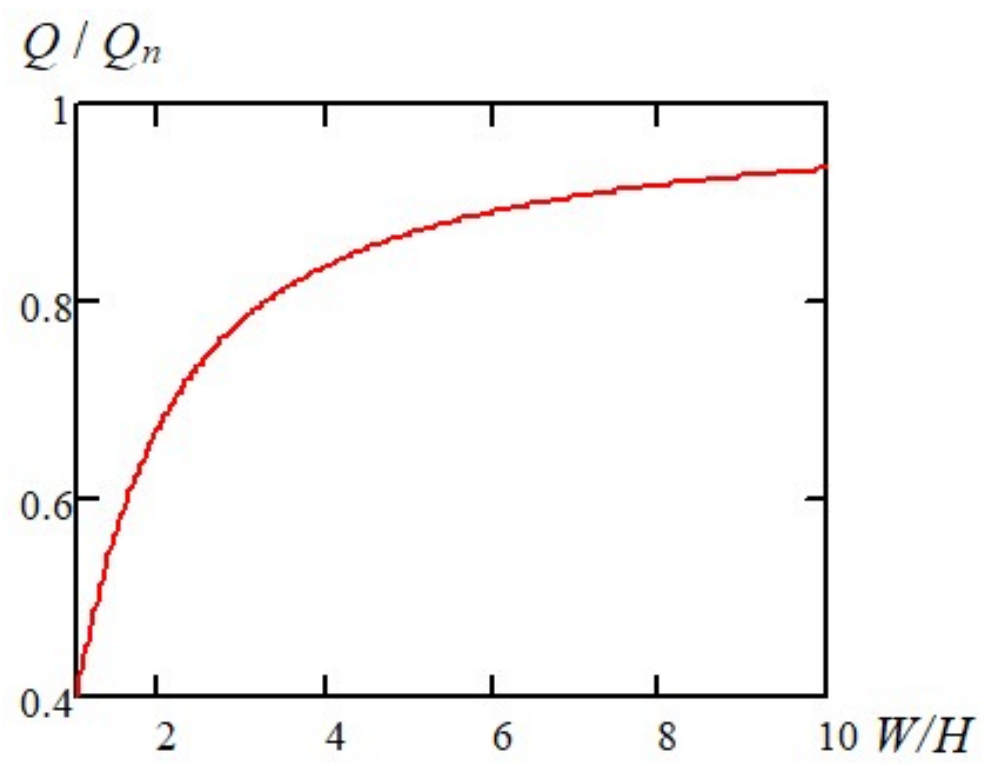

Рис. 3 - Графік залежності $Q / Q_{n}$ від $W / H$

Якщо ввести коефіцієнт зменшення витрати $K_{q}=Q / Q_{n}$, який враховує зменшення об'ємної витрати в каналі прямокутного поперечного перерізу порівняно з плином між плоскими паралельними пластинами, тоді можна записати формулу для визначення витрати в прямокутному каналі у спрощеному вигляді:

$$
Q_{n}=-\frac{K_{q}}{12 \mu} \cdot \frac{\partial p}{\partial z} H^{4}
$$

Для квадратного поперечного перерізу коефіцієнт зменшення витрати $K_{q}=0,4$.

Для розрахунку максимальної швидкості плину і витрати в центрі правильного чотирикутного пірамідального каналу скористаємось формулами для визначення швидкості плину $u_{r}$ між плоскими симетричними нерухомими стінками, які сходяться і об'ємної витрати через одиницю ширини такого каналу $q_{c}[6]:$

$$
\begin{gathered}
u_{r}=\frac{\rho g L_{1}^{2} L_{2}^{2}\left(\cos 2 \varphi_{0}-\cos 2 \varphi\right)}{2 \mu r \cos 2 \varphi_{0} \cos ^{2} \varphi_{0}\left(L_{1}+L_{2}\right)}, \\
q_{c}=\frac{\rho g L_{1}^{2} L_{2}^{2}\left(2 \varphi_{0} \cos 2 \varphi_{0}-\sin 2 \varphi_{0}\right)}{2 \mu \cos 2 \varphi_{0} \cos ^{2} \varphi_{0}\left(L_{1}+L_{2}\right)},
\end{gathered}
$$

де $r$ - поточний радіус, м; $\varphi$ - поточний кут, рад.; $\varphi_{0}$ - кут нахилу похилої стінки каналу до вертикалі, рад. $\left(\varphi_{0}<45^{\circ}\right) ; L_{1}-$ відстань від початку координат до вихідного зрізу бункера, м; $L_{2}-L_{1}-$ висота стовпа суміші в бункері, м; $\rho$ - густина рідини, кг $/ \mathrm{M}^{3} ; g=9,81 \mathrm{~m} / \mathrm{c}^{2}-$ прискорення сили тяжіння.

Максимальна швидкість буде в центральній частині такого каналу при $\varphi=0$, а формула (6) перетвориться на таку:

$$
u_{r c}=\frac{\rho g L_{1}^{2} L_{2}^{2}\left(\cos 2 \varphi_{0}-1\right)}{2 \mu r \cos 2 \varphi_{0} \cos ^{2} \varphi_{0}\left(L_{1}+L_{2}\right)} .
$$


Припустимо, що коефіцієнти $K_{u}$ i $K_{q}$ адекватно характеризують плин і у випадку похилих стінок каналу. Тоді, з урахуванням значень $K_{u}$ і $K_{q}$ для квадратного поперечного перерізу і виразів (7), (8), напишемо формули для розрахунку максимальної швидкості плину і об'ємної витрати в правильному чотирикутному пірамідальному каналі:

$$
\begin{gathered}
u_{r \max }=K_{u} u_{r c}=\frac{0,3 \rho g L_{1}^{2} L_{2}^{2}\left(\cos 2 \varphi_{0}-1\right)}{\mu r \cos 2 \varphi_{0} \cos ^{2} \varphi_{0}\left(L_{1}+L_{2}\right)}, \\
q=K_{q} q_{c} \cdot 2 L_{1} \operatorname{tg} \varphi_{0}=\frac{0,4 \rho g L_{1}^{3} L_{2}^{2}\left(2 \varphi_{0} \cos 2 \varphi_{0}-\sin 2 \varphi_{0}\right) \operatorname{tg} \varphi_{0}}{\mu \cos 2 \varphi_{0} \cos ^{2} \varphi_{0}\left(L_{1}+L_{2}\right)} .
\end{gathered}
$$

Розрахунок в'язкості бетонних сумішей в процесі віброекструзії

Для розрахунку в'язкості бетонної суміші при віброекструзії можна скористатися формулою (10), звідки:

$$
\mu=\frac{0,4 \rho g L_{1}^{3} L_{2}^{2}\left(2 \varphi_{0} \cos 2 \varphi_{0}-\sin 2 \varphi_{0}\right) \operatorname{tg} \varphi_{0}}{q \cos 2 \varphi_{0} \cos ^{2} \varphi_{0}\left(L_{1}+L_{2}\right)} .
$$

Недоліком розрахунку за формулою (11) є необхідність весь час експерименту підтримувати в каналі постійний рівень суміші $L_{2}$. Це ускладнює процес вимірювання, а при обмеженій кількості матеріалу він стає нездійсненим. Простіше розраховувати в'язкість за часом витікання $t_{6}$ певної кількості бетонної суміші.

Для цього опишемо витрату у правильному чотирикутному пірамідальному каналі через зміну рівня суміші на висоті z (рис. 1) диференційним рівнянням:

$$
q=S(z) \frac{d z}{d t}=4 z^{2} \operatorname{tg}^{2} \varphi_{0} \frac{d z}{d t}
$$

де $S(z)=4 z^{2} \operatorname{tg}^{2} \varphi_{0},-$ площа поперечного перерізу каналу.

Прирівнюємо рівняння (10) i (12):

$$
4 z^{2} \operatorname{tg}^{2} \varphi_{0} \frac{d z}{d t}=\frac{0,4 \rho g L_{1}^{3} L_{2}^{2}\left(2 \varphi_{0} \cos 2 \varphi_{0}-\sin 2 \varphi_{0}\right) \operatorname{tg} \varphi_{0}}{\mu \cos 2 \varphi_{0} \cos ^{2} \varphi_{0}\left(L_{1}+L_{2}\right)} .
$$

Звідки:

$$
d t=\frac{10 \mu \cos 2 \varphi_{0} \cos ^{2} \varphi_{0}\left(L_{1}+L_{2}\right) \operatorname{tg} \varphi_{0}}{\rho g L_{1}^{3} L_{2}^{2}\left(2 \varphi_{0} \cos 2 \varphi_{0}-\sin 2 \varphi_{0}\right)} z^{2} d z
$$

Для визначення часу витікання певної кількості суміші $t_{6}$ візьмемо інтеграли з обох частин виразу (13):

$$
\int_{0}^{t_{8}} d t=\frac{10 \mu \cos 2 \varphi_{0} \cos ^{2} \varphi_{0}\left(L_{1}+L_{2}\right) \operatorname{tg} \varphi_{0}}{\rho g L_{1}^{3} L_{2}^{2}\left(2 \varphi_{0} \cos 2 \varphi_{0}-\sin 2 \varphi_{0}\right)} \int_{L_{2}}^{L_{1}} z^{2} d z
$$

Звідки:

$$
t_{s}==\frac{5 \mu \sin 2 \varphi_{0} \cos 2 \varphi_{0}\left(L_{1}+L_{2}\right)\left(L_{1}^{3}-L_{2}^{3}\right)}{3 \rho g L_{1}^{3} L_{2}^{2}\left(2 \varphi_{0} \cos 2 \varphi_{0}-\sin 2 \varphi_{0}\right)}=C_{\kappa} \frac{\mu}{\rho g},
$$

де $C_{\kappa}=\frac{5 \sin 2 \varphi_{0} \cos 2 \varphi_{0}\left(L_{1}+L_{2}\right)\left(L_{1}^{3}-L_{2}^{3}\right)}{3 L_{1}^{3} L_{2}^{2}\left(2 \varphi_{0} \cos 2 \varphi_{0}-\sin 2 \varphi_{0}\right)}-$ конструктивний параметр, $\mathrm{M}^{-1}$. 
Тоді, з рівняння (14) визначимо формулу для розрахунку в'язкості бетонної суміші при віброекструзії:

$$
\mu=\frac{3 \rho g L_{1}^{3} L_{2}^{2}\left(2 \varphi_{0} \cos 2 \varphi_{0}-\sin 2 \varphi_{0}\right) t_{6}}{5 \sin 2 \varphi_{0} \cos 2 \varphi_{0}\left(L_{1}+L_{2}\right)\left(L_{1}^{3}-L_{2}^{3}\right)}=\frac{\rho g t_{s}}{C_{\kappa}} .
$$

Запропонована методика визначення в'язкості, разом з результатами попередньої роботи [7], розширює можливості досліджень реологічних властивостей бетонних сумішей в процесі віброекструзії різноманітних фібробетонних виробів.

Висновки. Отримані спрощені формули для розрахунку максимальної швидкості і витрати ньютонівських рідин при їх плині в прямокутних каналах постійного поперечного перерізу. Формули зручні для подальшої математичної обробки і не мають обмежень у застосуванні.

Розглянуто вплив форми прямокутних у поперечному перерізі каналів на характер плину ньютонівських рідин, на підставі чого запропоновані формули для розрахунку процесу плину бетонних сумішей в правильних чотирикутних пірамідальних каналах при віброекструзії.

Отримана формула для визначення в'язкості бетонних сумішей, які знаходяться під впливом вібрації, за часом їх витікання через правильні чотирикутні пірамідальні канали. Наведену методику розрахунку в'язкості можна використовувати для визначення реологічних характеристик будь-яких псевдоньютонівських рідин.

Перспективи подальших досліджень. У подальшому планується продовжити дослідження властивостей фібробетонних сумішей під впливом вібрації і експериментальна перевірка отриманих аналітичних результатів.

\section{Список використаної літератури}

1. Андреев И.А., Магазий П. Н. Вискозиметр для виброэкструдируемого фибробетона. Хим. машиностроение: Респ. межвед. науч.-техн. сб. Киев, 1987. Вып. 45. С. 95-99.

2. Андреєв I. А. Отримання спрощеної формули для опису ламінарної течії ньютонівської рідини в прямокутному каналі за допомогою «методу впливу». Наукові вісті НТУУ “КПІ”. Київ, 2010. №1. С. 8892.

3. Андреєв І. А., Смірнова К.О. Плин розчину в каналах дозатора-живильника віброекструзійної установки. Вісник національного технічного університету України “Київський політехнічний інститут", серія „Хімічна інженерія, екологія та ресурсозбереження”. Київ, 2010. № 2. С 17-20.

4. Андреєв І. А., Валуйскова С. С. Фібробетон. Удосконалення процесу отримання тонкого шару цементнопіщаного розчину під час віброекструзії. Хімічна промисловість України. Київ, 2012. №4 (111). С. 27-29.

5. Мак-Келви Д. М. Переработка полимеров. М.: Химия, 1965. 444 с.

6. Андреєв І. А., Лукач Ю. Е., Магазий П. Н. Процесс смешения при виброэкструзии фибробетона. Хим. машиностроение: Респ. межвед. науч.-техн. сб. Киев, 1989. Вып. 49. С. 34-37.

7. Andreiev I. A., Kramar A. V. Improvement of measurement of viscosity of concrete mixtures during vibro extrusion. Modern engineering and innovative technologies, Karlsruhe, 2020. Issue 12, Part 1, P.19-25. DOI: $10.30890 / 2567-5273.2020-12-01-023$.

Надійшла до редакції 14.03.2021

Andreiev I A., Pinchuk A. E., Kramar O. V.

\section{VIBROEXTRUSION FLOW OF CONCRETE MIXTURES IN A RIGHT FOUR-CORNER PYRAMIDAL CHANNEL}

The purpose of the research was to obtain calculation formulas for describing the flow of concrete mixtures and determining their viscosity directly in the process of vibroextrusion in regular quadrangular pyramidal channels. In solving the flow problems, it was taken into account that concrete mixtures are non-Newtonian systems in the conditions of a vibration field, and hydrodynamic theories were used to calculate the processes and rheological characteristics. 
Since the calculation formulas for describing the flow of fluids in a regular quadrangular pyramidal channel are absent and the channel has a square cross section, an analytical dependence was used to characterize the process, which describes the flow of a Newtonian fluid in a rectangular channel of constant cross section. The authors proposed for use simplified formulas for determining the maximum flow rate and flow rate of a Newtonian fluid in a channel of rectangular cross-section.

The degree of decrease in the flow velocity and the flow rates of a Newtonian fluid in a channel of rectangular crosssection in comparison with the flow between flat parallel plates are analyzed.

To describe the flow of concrete mixtures in regular quadrangular pyramidal channels, the proposed coefficients for reducing the speed and flow rate, as well as the existing formulas for the flow between flat symmetric stationary walls, which converge, were used.

The possibility of using the obtained formula for the flow rate in a regular quadrangular pyramidal channel for calculating the viscosity of a concrete mixture during vibration extrusion is shown. To simplify the experimental procedure, a new formula for calculating the viscosity based on the expiration time for a certain amount of concrete mixture has been proposed.

The formulas obtained are convenient for further mathematical processing and have no restrictions in their application. The proposed method for determining the viscosity expands the possibilities of studying the rheological properties of concrete mixtures in the vibroextrusion of fiber-reinforced concrete mixtures.

Keywords: flow of concrete, pyramidal channel, vibroextrusion, fiber-reinforced concrete mixture, viscosity.

\section{References}

1. Andreiev I.A., Magaziy P. N. (1987). Viscometer for vibro-extruded fiber-reinforced concrete. Chem. mechanical engineering: Rep. mezhved. scientific and technical Sat. Kiev. Issue. 45.S. 95-99.

2. Andreiev I. A. (2010). Obtaining a simplified formula for describing the laminar flow of Newtonian fluid in a rectangular channel using the "method of influence". Scientific news of NTUU "KPI". Kyiv. №1. Pp. 88-92.

3. Andreiev I. A., Smirnova K.O. (2010). The flow of solution in the channels of the feeder-feeder of the vibroextrusion unit. Bulletin of the National Technical University of Ukraine "Kyiv Polytechnic Institute", series "Chemical Engineering, Ecology and Resource Conservation". Kyiv. № 2. pp. 17-20.

4. Andreiev I. A., Valuyskova S.S. Fibrobeton. (2012). Improving the process of obtaining a thin layer of cementsand mortar during vibroextrusion. Cheerful prominence of Ukraine. Kiev. No. 4 (111). S. $27-29$.

5. McKelvey, D. M., (1965). Processing of polymers, Moscow, M: Khimiya.

6. Andreev IA, Lukach YE, Magaziy PN. (1989). Mixing process during vibroextrusion of fiber concrete. Chem. mechanical engineering: Resp. interscience. scientific and technical Sat Kiev. Issue. 49. pp. 34-37.

7. Andreiev I. A., Kramar O. V. (2020). Improvement of measurement of viscosity of concrete mixtures during vibro extrusion. Modern engineering and innovative technologies, Karlsruhe. Issue 12, Part 1, P.19-25. DOI: 10.30890/2567-5273.2020-12-01-023. 